ASTHMA

\title{
Gas chromatography/mass spectrometry analysis of exhaled leukotrienes in asthmatic patients
}

\author{
P Čáp, J Chládek, F Pehal, M Malý, V Petrů, P J Barnes, P Montuschi
}

Thorax 2004;59:465-470. doi: 10.1136/thx.2003.011866

See end of article for authors' affiliations

....................

Correspondence to:

Dr P Montuschi,

Department of

Pharmacology, Faculty of

Medicine, Catholic

University of the Sacred

Heart, Largo F Vito 1,

00168 Rome, Italy;

pmontuschi@rm.unicatt.it

Received 20 June 2003

Accepted

21 February 2004

\begin{abstract}
Background: Leukotriene-like immunoreactivity has been detected in exhaled breath condensate (EBC), but definitive evidence for the presence of leukotrienes (LTs) in this biological fluid is not available. A study was undertaken to determine whether $\mathrm{LTC}_{4}, \mathrm{LTD}_{4}$, $\mathrm{LTE}_{4}$, and $\mathrm{LTB}_{4}$ are measurable in EBC by gas chromatography/mass spectrometry and to quantify exhaled LTs in adults and children with asthma and in control subjects.

Methods: Twenty eight adults and 33 children with mild to moderate persistent asthma treated with inhaled corticosteroids and age matched healthy controls (50 adults and 50 children) were studied. LTB ${ }_{4}, \mathrm{LTC}_{4}$, $\mathrm{LTD}_{4}$, and $\mathrm{LTE}_{4}$ in EBC were measured by gas chromatography/mass spectrometry.

Results: $\mathrm{LTD}_{4}$, $\mathrm{LTE}_{4}$, and $\mathrm{LTB}_{4}$ were detectable in all samples. Concentrations of $\mathrm{LTC}_{4}$ in $E B C$ were either close to or below the detection limit of $1 \mathrm{pg} / \mathrm{ml}$. Median exhaled $\mathrm{LTD}_{4}, \mathrm{LTE}_{4}$, and $\mathrm{LTB}_{4}$ concentrations in asthmatic adults were increased 4.1-fold $(p<0.001), 1.8$-fold $(p<0.01)$, and 2.6-fold $(p<0.001)$, respectively, compared with values in healthy adults. Median exhaled $\mathrm{LTD}_{4}, \mathrm{LTE}_{4}$, and $\mathrm{LTB}_{4}$ concentrations in asthmatic children were increased 2.8-fold ( $p<0.001), 1.3$-fold $(p<0.001)$, and 1.6-fold $(p<0.001)$, respectively, compared with those in healthy children. In patients with asthma there was a correlation between exhaled $\mathrm{LTD}_{4}$ and $\mathrm{LTE}_{4}$ in both adults $(r=0.87, \mathrm{p}<0.0001)$ and children $(r=0.78, \mathrm{p}<0.0001)$. Conclusions: Gas chromatography/mass spectrometry can be used to accurately quantify exhaled LTs which are increased in asthmatic adults and children compared with controls.
\end{abstract}

L eukotrienes (LTs) $\mathrm{C}_{4}, \mathrm{D}_{4}$, and $\mathrm{E}_{4}$, known as cysteinyl(cys)leukotrienes, are important inflammatory mediators in -asthma and LT pathway modifiers are currently used in the treatment of asthma. ${ }^{12} \mathrm{LTB}_{4}$, a potent neutrophil chemoattractant, has weak effects on smooth muscle but it may contribute to airway narrowing by producing local neutrophil mediated oedema and mucus secretion. ${ }^{3}$ LTs have been measured in plasma, ${ }^{4}$ urine, ${ }^{5}{ }^{6}$ sputum, ${ }^{7}$ and bronchoalveolar lavage (BAL) fluid $^{8}{ }^{9}$ in patients with asthma. Plasma levels of $\mathrm{LTE}_{4}$ and sputum concentrations of cys-LTs are raised in asthmatic patients who also have higher BAL fluid concentrations of $\mathrm{LTB}_{4}$ and $\mathrm{LTC}_{4}$ than healthy subjects. ${ }^{48}$ Apart from one study which showed that the urinary $\mathrm{LTE}_{4}$ excretion rate is increased in asthmatic patients, ${ }^{6}$ no difference has generally been reported between baseline urinary $\mathrm{LTE}_{4}$ concentrations in healthy and atopic asthmatic subjects. ${ }^{5}$ Patients with nocturnal asthma have higher BAL fluid cys-LT and $\mathrm{LTB}_{4}$ concentrations and urinary $\mathrm{LTE}_{4}$ concentrations than control subjects. ${ }^{9}$

Measurement of exhaled breath condensate (EBC) is a method of sampling secretions from the airways which is completely non-invasive and potentially useful for quantifying lung inflammation in patients with pulmonary diseases including children. ${ }^{10}{ }^{11}$ Cys-LTs and $\mathrm{LTB}_{4}$ are increased in EBC in both adults and children with asthma compared with healthy controls. ${ }^{12-14}$ In these studies, exhaled LT concentrations were measured by different commercially available immunoassay kits which have not been validated by highly specific analytical methods such as high performance liquid chromatography or gas chromatography/mass spectrometry (GC/MS). This may partially explain the differences in absolute values of exhaled LTs reported in the different studies. There are no data on exhaled $\mathrm{LTC}_{4}$ and $\mathrm{LTD}_{4}$ levels in healthy subjects or in patients with asthma, and there are no large studies on exhaled LTs in the EBC from healthy subjects. The aim of the present study was to (1) ascertain if
GC/MS, the reference analytical method, can be used to measure LTs in EBC; (2) provide a quantitative assessment of exhaled $\mathrm{LTC}_{4}, \mathrm{LTD}_{4}, \mathrm{LTE}_{4}$ and $\mathrm{LTB}_{4}$ levels in adults and children with asthma; and (3) investigate possible differences in absolute concentrations of exhaled LT between adults and children with asthma.

\section{METHODS}

\section{Study subjects}

Patients with asthma were recruited from the Allergy and Clinical Immunology outpatient clinic at the Hospital Na Homolce in Prague. Four groups of subjects were studied: 28 adults with stable asthma, 50 healthy adults, 33 children with stable asthma, and 50 healthy children. Healthy controls were matched for age. Informed consent was obtained from all adults and children's parents. The study was approved by the ethics committee of the Hospital Na Homolce in Prague, the Czech Republic.

The diagnosis and classification of asthma was based on clinical history and examination and pulmonary function parameters, according to international guidelines. ${ }^{15}$ Asthmatic patients had mild to moderate persistent asthma and were on maintenance treatment with inhaled corticosteroids. No asthmatic patients had received leukotriene antagonists in the previous 4 weeks and had no upper respiratory tract infections in the previous 4 weeks. No study subjects had received non-steroidal anti-inflammatory drugs in the previous 2 weeks.

Healthy adults were staff members and healthy children were recruited from staff member children or were contacted during their visits to the dental care facility. A parent was interviewed to confirm the lack of past or present lower respiratory disease and atopy.

Abbreviations: $E B C$, exhaled breath condensate; $G C / M S$, gas chromatography/mass spectrometry; LT, leukotriene 


\section{Study design}

The study was of cross sectional design. Subjects attended the Allergy and Clinical Immunology outpatient clinic at the Hospital Na Homolce in Prague on one occasion for clinical examination, spirometric tests, and EBC collection.

\section{Pulmonary function}

Spirometric tests were performed using a dry spirometer (Masterscreen IOS, Jaeger, Höchberg, Germany) and the best of three manoeuvres was expressed as the absolute value (in litres) and as a percentage of the predicted value.

\section{EBC collection}

EBC samples were collected using a specially designed condensing chamber as previously described (Ecoscreen, Jaeger, Hoechberg, Germany). ${ }^{16}$ Subjects breathed tidally through a mouthpiece connected to the condenser for 15 minutes while wearing nose clips. Samples were stored at $-80^{\circ} \mathrm{C}$ before LT measurements. The volume of the EBC samples ranged from 1 to $2 \mathrm{ml}$. Contamination of saliva in EBC was determined by the colorimetric detection of $\alpha$ amylase ( $\alpha$-Amylase-Liquid BIO-LA-TEST kit, Pliva-Lachema, Czech Republic).

\section{GC/MS of leukotrienes in EBC}

$\mathrm{LTB}_{4}$ and cys-LTs were analysed by GC/MS after derivatisation with ethylchloroformate and liquid-liquid extraction. This method has been successfully used in modified versions for rapid derivatisation and GC/MS analysis of amino acids, hydroxycarboxylic acids, and long chain fatty acids. ${ }^{17-19}$ All chemicals were obtained from Sigma-Aldrich (Prague, Czech Republic). Standard solutions were prepared in water. Internal standard solutions were prepared by dissolving arachidonic acid in water. Arachidonic acid was used as the internal standard because it is structurally similar to LTs, is undetectable in EBC processed without the addition of arachidonic acid, and is stable in aqueous solutions. Glass reaction vials were silanised with a $10 \%$ solution of dichlorodimethylsilane in hexane (30 minutes at room temperature) and washed with denatured alcohol, water, and acetone before use.

EBC $(500 \mu \mathrm{l})$ was treated with $20 \mu \mathrm{l}$ ethylchloroformate and $40 \mu \mathrm{l}$ pyridine while shaking for a few seconds to evaporate carbon dioxide. Following the addition of $0.25 \mathrm{ml}$ chloroform and $0.5 \mathrm{ml}$ sodium carbonate-bicarbonate solution ( $1 \mathrm{~mol} / \mathrm{l}, \mathrm{pH} 10)$, the tube was shaken for 10 seconds and left to reach phase equilibrium by standing for $2-$ 3 minutes. Finally, the upper aqueous layer was aspirated off and the organic phase dried by adding $50-80 \mathrm{mg}$ sodium sulfate. The volume was reduced to approximately 80-100 $\mu \mathrm{l}$ under a stream of nitrogen at $40^{\circ} \mathrm{C}$ for 3 minutes. An aliquot of $2-3 \mu \mathrm{l}$ was then injected into the fused silica capillary column $8 \mathrm{~m} \times 0.25 \mathrm{~mm}$ (Optima $\delta$-3 type; Macherey-Nagel, Germany) in the split-less mode. The liquid phase was ZB-5 ( $5 \%$ phenyl polysiloxan) and film thickness was $0.25 \mu \mathrm{m}$. Carrier gas pressure head was 4.5 psi. The initial column temperature was $80^{\circ} \mathrm{C}$ and the injector temperature was $280^{\circ} \mathrm{C}$. The column was held for 1.5 minutes at $80^{\circ} \mathrm{C}$, after which the temperature was increased to $340^{\circ} \mathrm{C}$ at the rate of $28^{\circ} \mathrm{C} / \mathrm{min}$. The ethyl esters (ethoxycarbonyl esters) of all LTs studied and of arachidonic acid (internal standard) are sufficiently volatile for GC analysis. The ion current chromatograms for the internal standard and each of the LTs obtained during GC/MS analysis are shown in fig 1 . The elution order and retention times were as follows: arachidonic acid (internal standard), $6.8 \mathrm{~min} ; \mathrm{LTB}_{4}, 9.6 \mathrm{~min}$; $\mathrm{LTE}_{4}$, $12.7 \mathrm{~min}, \mathrm{LTD}_{4}, 16.8 \mathrm{~min} ; \mathrm{LTC}_{4}, 24.2 \mathrm{~min}$ (fig 1). Tandem GC/MS (type 120, Finnigan Mat Co, San José, USA) was operated in electron ionisation $(70 \mathrm{eV})$ mode with selected ion monitoring mode used for high sensitivity data acquisition using an MS detector for single quadrupole GC/MS systems (Trace DSQ, Finnigan Mat Co). Ion fragments m/z 91 and $\mathrm{m} / \mathrm{z} 69$ were used to monitor internal standard and LTs, respectively. Fragmentations of arachidonic acid, $\mathrm{LTB}_{4}, \mathrm{LTD}_{4}$, and $\mathrm{LTE}_{4}$ are shown in figs 2 and 3. The basis for selecting the ions monitored was the highest sensitivity. The detection limit with a signal to noise ratio of 5 was $1 \mathrm{pg} / \mathrm{ml}$. The linearity of the detector response was confirmed over the concentration range $5-1000 \mathrm{pg} / \mathrm{ml}$. The correlation coefficients of the standard curves were $r^{2}=0.925$ for $\mathrm{LTB}_{4}$, $r^{2}=0.918$ for $\mathrm{LTD}_{4}$, and $r^{2}=0.951$ for $\mathrm{LTE}_{4}$.

The overall reproducibility of the procedure, expressed as the coefficient of variation, was determined from 10 independent analyses of the standards which were analysed in duplicate. Coefficients of variation for $\mathrm{LTB}_{4}, \mathrm{LTD}_{4}$, and $\mathrm{LTE}_{4}$ were $5.2 \%, 8.4 \%$, and $4.9 \%$, respectively. The within-day reproducibility of the EBC profiling was assessed in $20 \mathrm{EBC}$ samples from the study which were analysed in duplicate. The coefficients of variation for $\mathrm{LTB}_{4}, \mathrm{LTD}_{4}$, and $\mathrm{LTE}_{4}$ measurement were $<10 \%$. The recovery of arachidonic acid, $\mathrm{LTB}_{4}, \mathrm{LTD}_{4}$, and $\mathrm{LTE}_{4}$ from EBC samples was assessed in spiked quality control samples $(n=20)$ and was $>92 \%$.

\section{Statistical analysis}

Statistical analysis was performed using Statistica Version 6.0 (StatSoft Inc, Tulsa, USA). LT concentrations were expressed as medians and interquartile ranges (25th to 75 th percentiles). Statistical significance was defined as a value of $p<0.05$. Kruskal-Wallis test followed by pairwise MannWhitney U tests were used to compare groups. Correlations between variables were evaluated by Spearman test. The relationship between age and the different LTs was analysed by a $y=a+b^{\star} \log ($ age $)$ regression model.

\section{RESULTS}

The characteristics of the asthmatic and healthy subjects are shown in table 1.

No amylase activity $(<22 \mathrm{U} / \mathrm{ml})$ was detected in any study sample, excluding significant salivary contamination. $\mathrm{LTD}_{4}$, $\mathrm{LTE}_{4}$, and $\mathrm{LTB}_{4}$ were detected in EBC in healthy subjects and patients with asthma using GC/MS. LTC $_{4}$ was either undetectable or was close to the detection limit in most of the samples. Median (interquartile range) concentrations of

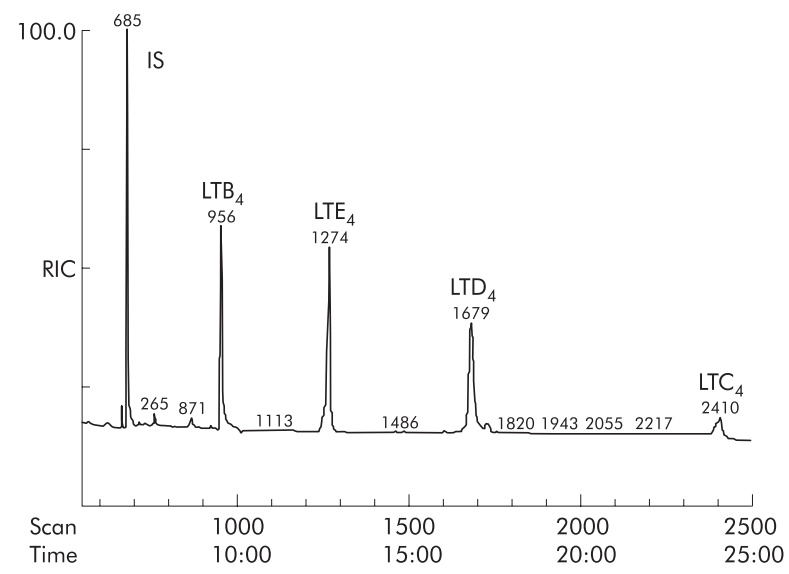

Figure 1 lon current chromatograms for arachidonic acid (internal standard, IS), $\mathrm{LTB}_{4}, \mathrm{LTC}_{4}, \mathrm{LTD}_{4}$, and $\mathrm{LTE}_{4}$ obtained during GC/MS analysis. An analytical pure water sample (1 ml) was spiked with $80 \mathrm{pg}$ of each LT and $300 \mathrm{pg}$ of arachidonic acid. After derivatisation and extraction, a volume of $2.5 \mu \mathrm{l}$ was injected onto the GC column. GC/MS analysis was performed using an MS detector for single quadrupole systems (see details in the text). 

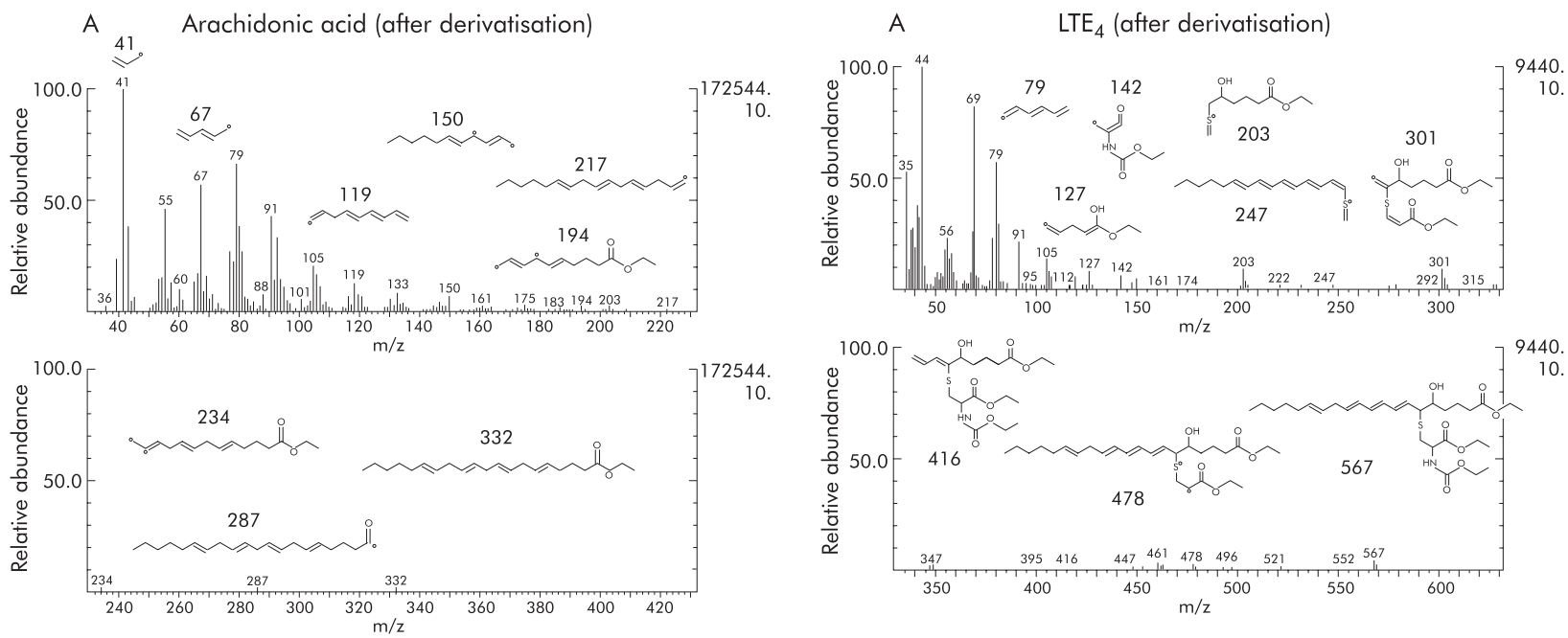

172544.
10.
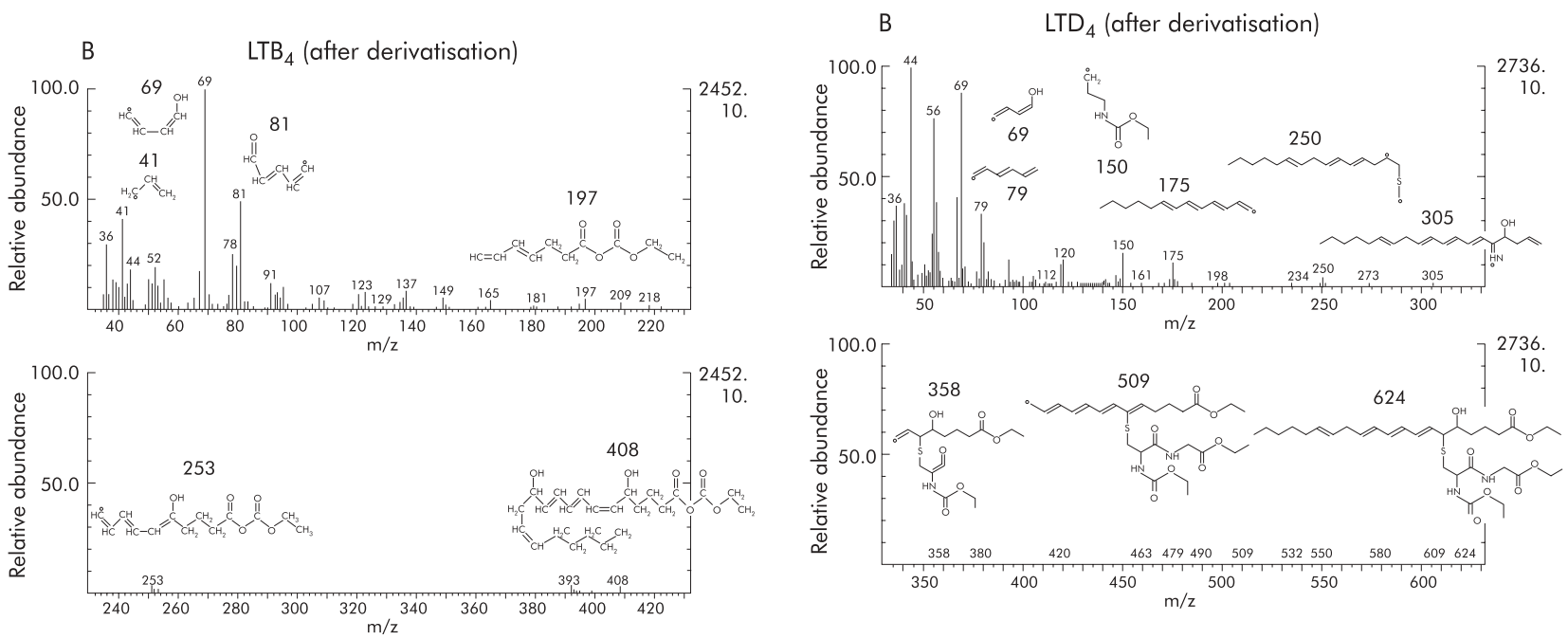

Figure 2 Electron ionisation mass spectra of (A) arachidonic acid and (B) $\mathrm{LTB}_{4}$.

exhaled LTs were increased in both asthmatic adults $\left(\mathrm{LTD}_{4}\right.$ : 33 (11-52) pg/ml, p<0.001 (fig 4); $\mathrm{LTE}_{4}: 135$ (82-192) pg/ml, $\mathrm{p}<0.01$ (fig 5); $\mathrm{LTB}_{4}: 205$ (122-369) pg/ml, p<0.001 (fig 6)) and children $\left(\mathrm{LTD}_{4}: 11\right.$ (6-15) pg/ml, p $<0.001$ (fig 4); $\mathrm{LTE}_{4}$ : 79 (68-110) pg/ml, p<0.001 (fig 5); LTB 4 : 109 (103-115) pg/ $\mathrm{ml}, \mathrm{p}<0.001$ (fig 6)) compared with age matched healthy controls (adults: $\mathrm{LTD}_{4}: 8$ (5-10) pg/ml (fig 4); $\mathrm{LTE}_{4}: 74$ (6585) $\mathrm{pg} / \mathrm{ml}$ (fig 5); $\mathrm{LTB}_{4}: 79$ (71-90) pg/ml (fig 6); children: $\mathrm{LTD}_{4}: 4$ (3-5) pg/ml (fig 4); LTE ${ }_{4}: 59$ (51-71) pg/ml (fig 5); $\mathrm{LTB}_{4}: 69(65-76) \mathrm{pg} / \mathrm{ml}$ (fig 6)).

Exhaled $\mathrm{LTC}_{4}$ concentrations were undetectable in 13 of 28 asthmatic adults, 23 of 33 asthmatic children, 36 of 50 healthy adults, and 27 of 50 healthy children (fig 7). In those subjects in whom $\mathrm{LTC}_{4}$ was measurable, concentrations were close to the detection limit $(3.0$ (2-3.5) $\mathrm{pg} / \mathrm{ml}$ (asthmatic adults) $v 1.5(1.0-2.0) \mathrm{pg} / \mathrm{ml}$ (healthy adults $), \mathrm{p}=\mathrm{NS} ; 3.0(0-$ $4.5) \mathrm{pg} / \mathrm{ml}$ (asthmatic children) $v l^{1.0} \quad(1.0-2.0) \mathrm{pg} / \mathrm{ml}$ (healthy children), $\mathrm{p}<0.01$, fig 7 ).

In healthy subjects, concentrations of $\mathrm{LTD}_{4}(\mathrm{p}<0.05), \mathrm{LTE}_{4}$ $(\mathrm{p}<0.001)$, and $\mathrm{LTB}_{4}(\mathrm{p}<0.05)$ in EBC were higher in adults than in children (figs 4,5 , and 6 ). In asthmatic patients median exhaled $\mathrm{LTD}_{4}, \mathrm{LTE}_{4}$, and $\mathrm{LTB}_{4}$ concentrations were 3 fold, 1.7-fold, and 1.9-fold higher in adults than in children, respectively, although these differences did not reach statistical significance. In healthy subjects exhaled $\mathrm{LTD}_{4}$ $\mathrm{LTE}_{4}$ and $\mathrm{LTB}_{4}$ concentrations increased with age. This

Figure 3 Electron ionisation mass spectra of $(A) L_{T E}$ and $(B) L_{T} D_{4}$.

increase was non-linear and was marked in children but slower in adults following a logarithmic model (table 2).

In patients with asthma there was a correlation between $\mathrm{LTD}_{4}$ and $\mathrm{LTE}_{4}$ concentrations in EBC in both adults $(r=0.87, \mathrm{p}<0.0001)$ and children $(r=0.78, \mathrm{p}<0.0001)$, but no correlation between exhaled $\mathrm{LTD}_{4}$ and $\mathrm{LTB}_{4}$ concentrations was observed in any study groups. There was a weak correlation between exhaled $\mathrm{LTE}_{4}$ and $\mathrm{LTB}_{4}$ concentrations in healthy adults $(r=0.35, \mathrm{p}<0.05)$ and children $(r=0.41$, $\mathrm{p}<0.05$ ), but not in either asthmatic adults or children. There was no correlation between exhaled LTs and lung function in any study group.

\section{DISCUSSION}

In this study we measured $\mathrm{LTD}_{4}, \mathrm{LTE}_{4}$, and $\mathrm{LTB}_{4}$ concentrations in EBC in adults and children with mild to moderate persistent asthma and in healthy age matched controls using GC/MS. The concentrations of $\mathrm{LTD}_{4}$ and $\mathrm{LTE}_{4}$ in EBC were increased in both groups of patients with asthma. Increased $\mathrm{LTD}_{4}$ and $\mathrm{LTE}_{4}$ concentrations in EBC are consistent with a role for cys-LTs in the pathophysiology of this disease. ${ }^{20}$ Interestingly, these inflammatory mediators were increased in patients with asthma who had normal lung function and were treated with inhaled corticosteroids. Whether the increase in exhaled LTs under these circumstances reflects ongoing airway inflammation requires further investigation. We have also shown that $\mathrm{LTB}_{4}$ levels in EBC are raised in 
Table 1 Characteristics of study subjects

\begin{tabular}{|c|c|c|c|c|}
\hline \multirow[b]{2}{*}{ Characteristic } & \multicolumn{2}{|l|}{ Healthy subjects } & \multicolumn{2}{|l|}{ Asthmatics } \\
\hline & Children $(n=50)$ & Adults $(n=50)$ & Children $(n=33)$ & Adults ( $n=28$ ) \\
\hline Age (years) & $8.7(0.4)$ & $37.6(1.6)$ & $8.9(0.4)$ & $40.4(2.9)$ \\
\hline $\operatorname{Sex}(M / F)$ & $24 / 26$ & $14 / 36$ & $22 / 11$ & $16 / 12$ \\
\hline $\mathrm{FEV}_{1}(\%$ predicted $)$ & $98.7(1.9)$ & $107.3(1.8)$ & $107.3(2.5)$ & $95.1(2.8)$ \\
\hline FVC (\% predicted) & $86.6(1.5)$ & 104.5 (1.9) & $97.4(2.7)$ & $98.7(2.4)$ \\
\hline $\mathrm{MEF}_{50}(\%$ predicted) & $102.3(3.7)$ & $99.3(3.1)$ & $90.3(3.4)$ & $72.1(3.9)$ \\
\hline $\mathrm{MEF}_{25-75}(\%$ predicted) & $113.9(3.4)$ & $100.7(2.9)$ & $97.3(3.8)$ & $75.9(4.1)$ \\
\hline \multirow[t]{2}{*}{ Inhaled corticosteroids ( $\mu \mathrm{g} /$ day) } & None & None & BDP: $250-500$ & BDP: $500-1000$ \\
\hline & & & BUD: $200-400$ & BUD: $400-800$ \\
\hline
\end{tabular}

Data are shown as mean (SE) values.

$\mathrm{BDP}=$ beclomethasone dipropionate; $\mathrm{BUD}=$ budesonide; $\mathrm{FEV}_{1}=$ forced expiratory volume in 1 second;

$\mathrm{FVC}=$ forced vital capacity; $\mathrm{MEF}=$ mid expiratory flow rate.

asthmatics of both age groups, with no overlap in $\mathrm{LTB}_{4}$ concentrations between asthmatics and controls. These findings are in agreement with a previous study which reported increased concentrations of exhaled $\mathrm{LTB}_{4}$ in children with mild persistent asthma who were treated with inhaled steroids, but not in steroid naïve children with mild intermittent asthma. ${ }^{14}$

Among the cells constitutively present in the airways, cysLTs are mainly produced by mast cells and macrophages. ${ }^{1}$ Eosinophils, which are not present in the airways of healthy subjects, migrate into the airways of asthmatic patients in large numbers and may synthesise cys-LTs as well as $\mathrm{LTB}_{4} \cdot{ }^{1}$ Neutrophils may produce $\mathrm{LTB}_{4}$, but not cys-LTs, because they lack the synthase to convert $\mathrm{LTA}_{4}$ to $\mathrm{LTC}_{4}{ }^{1}$ EBC analysis cannot provide any information on the cellular origin of mediators. ${ }^{21}$ For this reason, we were unable to ascertain the cellular source of LTs in EBC for which invasive studies such as bronchial biopsies are required.

This study provides, for the first time, a quantitative assessment of $\mathrm{LTD}_{4}, \mathrm{LTE}_{4}$, and $\mathrm{LTB}_{4}$ in EBC in a large group of healthy subjects and in patients with asthma using GC/MS which is the reference analytical method. The derivatisation extraction procedure is rapid and proceeds at room temperature. The recovery of arachidonic acid, used as an internal standard, and for LTs was higher than 92\%. Arachidonic acid was used as the internal standard because it is structurally similar to the LTs, is undetectable in EBC, and because of low cost. However, this approach has limitations that need to be addressed in future studies. The principal drawback of our methodology is that the stable isotope dilution method was

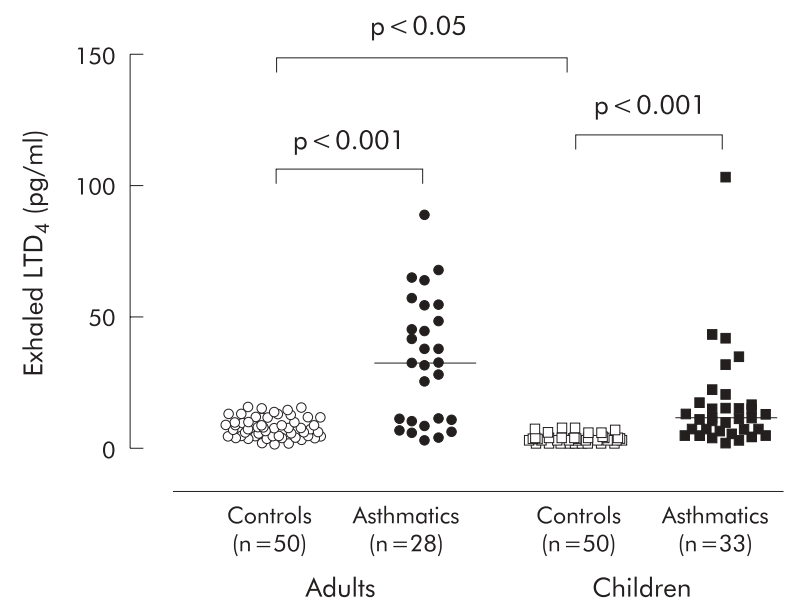

Figure $4 \quad \mathrm{LTD}_{4}$ concentrations in exhaled breath condensate in healthy adults, adults with asthma, healthy children, and children with asthma. Median values are shown by horizontal bars. not used. Arachidonic acid is not chemically identical to LTs and may behave differently during sample preparation. As a precursor of the LTs, arachidonic acid could be present in the EBC, thus leading to an overestimation of LT concentrations in this biological fluid. However, in the EBC samples analysed without the addition of the internal standard, arachidonic acid was undetectable. In any case, stable isotope dilution methods should be used to overcome these problems as well as a second stable isotope of the analytes to rule out artifactual generation or detection of LTs. Despite these methodological limitations, this study may prompt future studies aimed at improving GC/MS methods of LT analysis in EBC. Although it is expensive, time consuming, and not suitable for routine use, mass spectrometry may be valuable for validating immunoassays for LTs. Validation of immunoassays for LTs in EBC is essential for their large scale use and the development of LT analysis in EBC.

$\mathrm{LTE}_{4}$ concentrations in EBC were higher in our study than in previously reported studies in similar groups of subjects. ${ }^{12-14}$ Possible sources of variability in exhaled LT concentrations include differences in EBC collection, sample storage, analytical techniques, and severity of asthma at the time of EBC collection. ${ }^{11}$ As in most of the published studies on exhaled biomarkers, LT concentrations are given per ml EBC. Expressing LT values as concentration units may have limitations since many factors are likely to affect differentially the volume of EBC and the concentrations of various compounds in it. As pointed out by Effros et al, ${ }^{22}$ part of the

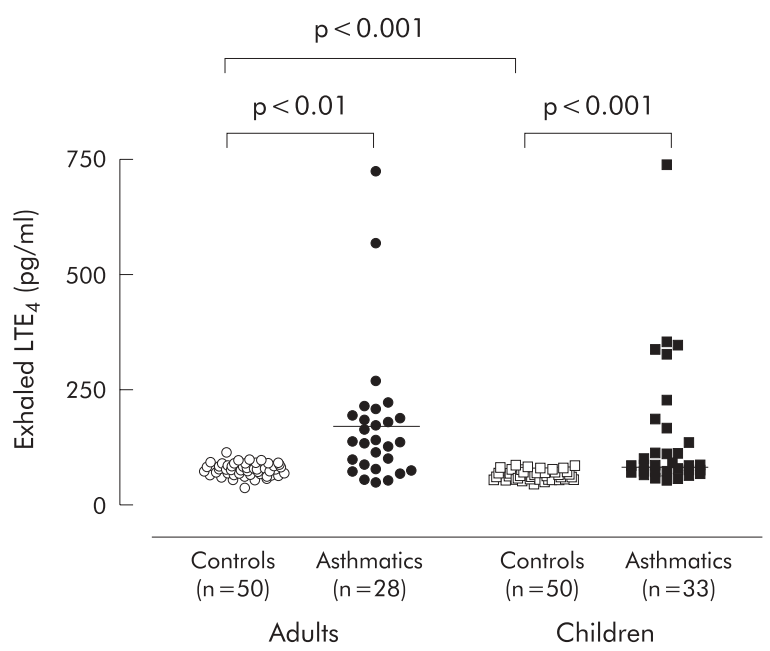

Figure $5 \mathrm{LTE}_{4}$ concentrations in exhaled breath condensate in healthy adults, adults with asthma, healthy children, and children with asthma. Median values are shown by horizontal bars. 


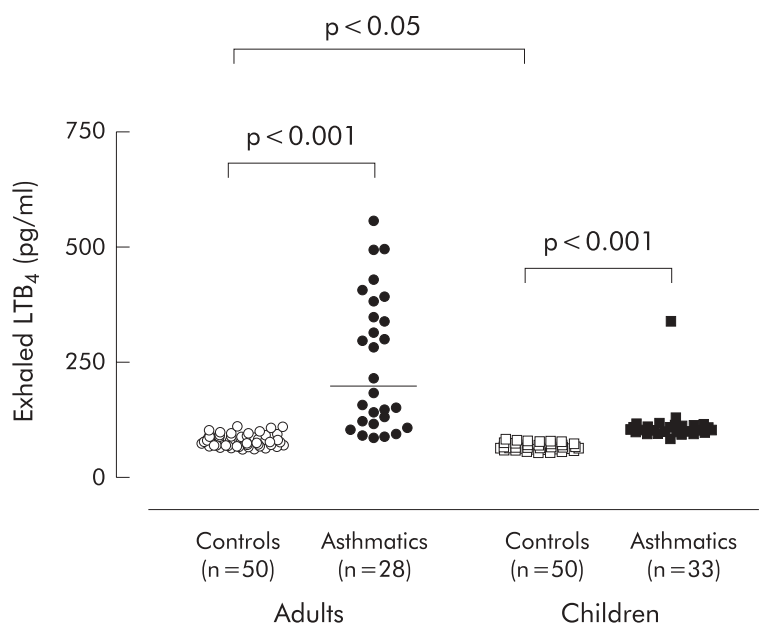

Figure $6 \mathrm{LTB}_{4}$ concentrations in exhaled breath condensate in healthy adults, adults with asthma, healthy children, and children with asthma. Median values are shown by horizontal bars.

variation in non-volatile compound concentrations in EBC can be related to differences in the dilution of respiratory droplets by water vapour. The lack of correlation between structurally related compounds such as $\mathrm{LTD}_{4}$ and $\mathrm{LTB}_{4}$ observed in this study and the selective increase of LTs in the single subject previously reported ${ }^{23}$ do not seem to support this evidence. However, reference indicators such as measurement of conductivity as proposed by Effros et al la $^{24}$ should be used in future studies aimed at quantifying exhaled LTs. Alternatively, LT values in EBC can be expressed as total amount of the eicosanoid expired over a standard period of collection. ${ }^{12}$ At present, due to the lack of a standardised procedure for $\mathrm{EBC}$ collection and validated analytical methods, comparisons of data obtained in different laboratories are difficult. ${ }^{11}$ EBC analysis is currently more reliable for relative measures than for determining absolute levels of inflammatory mediators.

Median exhaled $\mathrm{LTE}_{4}$ concentrations were 4-12 fold higher than $\mathrm{LTD}_{4}$ concentrations, whereas $\mathrm{LTC}_{4}$ was undetectable in about $50 \%$ of subjects and close to the detection limit of the assay in the others. The fact that exhaled $\mathrm{LTC}_{4}$ concentrations were virtually undetectable and that $\mathrm{LTE}_{4}$ was the most abundant cys-LT in the EBC is consistent with a rapid and

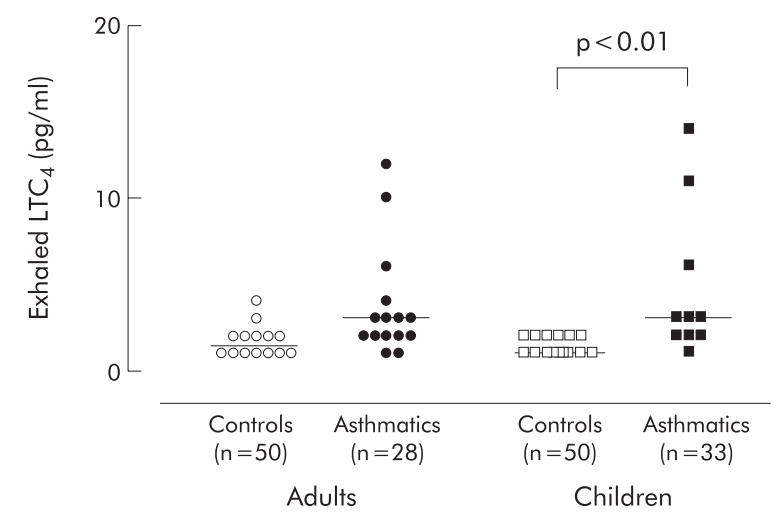

Figure $7 \quad \mathrm{LTC}_{4}$ concentrations in exhaled breath condensate in healthy adults, adults with asthma, healthy children, and children with asthma. Median values are shown by horizontal bars. Only detectable exhaled $\mathrm{LTC}_{4}$ concentrations are shown. Exhaled $\mathrm{LTC}_{4}$ concentrations were undetectable in 13 adults with asthma, 23 children with asthma, 36 healthy adults, and 27 healthy children.
Table 2 Relationships between leukotrienes in exhaled breath condensate and age

\begin{tabular}{|c|c|c|c|c|}
\hline & \multicolumn{2}{|c|}{ Coefficients: $L T=a+b * \log ($ age $)$} & \multicolumn{2}{|c|}{ Characteristics of fit } \\
\hline & a (SE) & b (SE) & $\begin{array}{l}p \text { value } \\
\text { (F test) }\end{array}$ & $R^{2}$ \\
\hline $\mathrm{LTB}_{4}$ & $56.40(4.05)$ & $6.68(1.37)$ & $<0.0001$ & 0.195 \\
\hline $\mathrm{LTD}_{4}$ & $-1.16(1.13)$ & $2.50(0.38)$ & $<0.0001$ & 0.304 \\
\hline $\mathrm{LTE}_{4}$ & $45.00(4.60)$ & $8.04(1.56)$ & $<0.0001$ & 0.214 \\
\hline
\end{tabular}

complete pulmonary metabolism of $\mathrm{LTC}_{4}$ to $\mathrm{LTE}_{4}$, which seems to be the end product of cys-LT metabolism in the lung. ${ }^{5}$ A similar pattern of LT concentrations has been reported in plasma and urine..$^{5}$ The strong correlation between $\mathrm{LTD}_{4}$ and $\mathrm{LTE}_{4}$ in both adults $(r=0.87)$ and children $(r=0.78)$ with asthma is consistent with a common metabolic pathway, whereas the lack of correlation between cys-LTs and $\mathrm{LTB}_{4}$ in the same groups of patients might reflect the involvement of different mechanisms in the airway inflammatory process.

Concentrations of LTs in EBC in healthy subjects increased with age, indicating either an increased production or a lower clearance of these compounds in adults. Compared with children, median exhaled LT concentrations were higher in adults, reaching statistical significance in healthy subjects. The lack of a statistically significant difference in exhaled LTs between adults and children with asthma could be explained by a higher variability in LT concentrations and a lower number of subjects in the asthmatic groups.

Because of a lack of steroid naïve asthmatic subjects we were unable to assess the effect of inhaled corticosteroids on LT concentrations in EBC in both adults and children with asthma. However, inhaled corticosteroids do not seem to suppress the LT pathway. A previous study has shown similar exhaled cys-LT concentrations in steroid naïve and steroid treated aspirin tolerant asthmatic adults. ${ }^{25}$ Although controlled studies are required, these findings might indicate that exhaled LTs are relatively resistant to inhaled corticosteroids and that they might be useful non-invasive markers of airway inflammation in steroid treated asthmatic patients. Measurement of LTs in EBC is a non-invasive method that could clarify the effects of corticosteroids and other antiinflammatory drugs on these important mediators in asthma.

In conclusion, we have shown that $\mathrm{LTD}_{4}, \mathrm{LTE}_{4}$, and $\mathrm{LTB}_{4}$ are detectable in EBC in healthy adults and children using GC/MS. Exhaled LT concentrations increase with age in healthy subjects. LT concentrations in EBC are increased in both adults and children with asthma compared with age matched healthy controls.

\section{Authors' affiliations}

P Cáp, F Pehalm, V Petrů, Department of Allergology and Clinical Immunology, Hospital Na Homolce, Prague, Czech Republic J Chládek, Department of Pharmacology, Faculty of Medicine, Charles University, Prague, Czech Republic

M Malý, State Institute of Public Health, Prague, Czech Republic P J Barnes, Department of Thoracic Medicine, Imperial College School of Medicine at the National Heart and Lung Institute, London, UK P Montuschi, Department of Pharmacology, Faculty of Medicine, Catholic University of the Sacred Heart, Rome, Italy

This work was funded by grant no. NL/7024-3 from the Czech Ministry of Health Care and by academic funds 2003-2004 from the Catholic University of the Sacred Heart.

This work was performed in the Department of Allergology and Clinical Immunology, Hospital Na Homolce, Prague, Czech Republic. 


\section{REFERENCES}

1 Leff AR. Role of leukotrienes in bronchial hyperresponsiveness and cellular responses in airways. Am J Respir Crit Care Med 2000;161:S125-32.

2 Drazen JM, Israel E, O'Byrne PM. Treatment of asthma with drugs modifying the leukotriene pathway. N Engl J Med 1999;340:197-206.

3 Busse WW. Leukotrienes and inflammation. Am J Respir Crit Care Med 1998;157:S210-3.

4 Chavis $C$, van Vyve $T$, Chanez $P$, et al. Leukotriene $E_{4}$ plasma levels in adult asthmatic patients with variable disease severity. Allergy 1997;52:589-92.

5 Kumlin M. Measurement of leukotrienes in humans. Am J Respir Crit Care Med 2000;161:S102-6.

6 Asano K, Lilly CM, O'Donnell WJ, et al. Diurnal variation of urinary leukotriene $\mathrm{E}_{4}$ and histamine excretion rates in normal subjects and patients with mild-to-moderate asthma. J Allergy Clin Immunol 1995;96:643-51.

7 Pavord ID, Ward R, Woltmann G, et al. Induced sputum eicosanoid concentrations in asthma. Am J Respir Crit Care Med 1999;160:1905-9.

8 Wardlaw AJ, Hay H, Cromwell O, et al. Leukotrienes, $\mathrm{LTC}_{4}$ and $\mathrm{LTB}_{4}$ in bronchoalveolar lavage in bronchial asthma and other respiratory diseases. $J$ Allergy Clin Immunol 1989;84:19-26.

9 Wenzel SE, Trudeau JB, Kaminsky DA, et al. Effect of 5-lipoxygenase inhibition on bronchoconstriction and airway inflammation in nocturnal asthma. Am J Respir Crit Care Med 1995;152:897-905.

10 Mutlu GM, Garey KW, Robbins RA, et al. Collection and analysis of exhaled breath condensate in humans. Am J Respir Crit Care Med 2001;164:731-7.

11 Montuschi P. Indirect monitoring of lung inflammation. Nat Rev Drug Discov 2002;1:238-42.

12 Montuschi P, Barnes PJ. Exhaled leukotrienes and prostaglandins in asthma. $J$ Allergy Clin Immunol 2002; 109:615-20.

13 Hanazawa T, Kharitonov SA, Barnes PJ. Increased nitrotyrosine in exhaled breath condensate of patients with asthma. Am J Respir Crit Care Med 2000;162:1273-6.
14 Csoma Z, Kharitonov SA, Balint B, et al. Increased leukotrienes in exhaled breath condensate in childhood asthma. Am J Respir Crit Care Med 2002;166:1345-9.

15 National Heart, Lung and Blood Institute. Global strategy for asthma management and prevention. WHO/NHLBI workshop report. Publication no 95-3659. Bethesda, MD: National Institutes of Health, 1995.

16 Montuschi P, Collins JV, Ciabattoni G, et al. Exhaled 8-isoprostane as an in vivo biomarker of lung oxidative stress in patients with COPD and healthy smokers. Am J Respir Crit Care Med 2000;162:1175-7.

17 Husek P. Amino acid derivatization and analysis in five minutes. FEBS Lett 1991;280:354-6.

18 Husek P. Chloroformates in gas chromatography as general purpose derivatizing agents. J Chromatogr B Biomed Sci Appl 1998;717:57-91.

19 Husek P. Long-chain fatty acids esterified by action of alkyl chloroformates and analysed by capillary gas chromatography. J Chromatogr 1993:615:334-8.

20 Barnes PJ, Chung KP, Page PC. Inflammatory mediators of asthma: an update. Pharmacol Rev 1998;50:515-96.

21 Montuschi P, Barnes PJ. Analysis of exhaled breath condensate for monitoring airway inflammation. Trends Pharmacol Sci 2002;23:232-7.

22 Effros RM, Hoagland KW, Bosbous M, et al. Dilution of respiratory solutes in exhaled condensates. Am J Respir Crit Care Med 2002; 165:663-9.

23 Montuschi $\mathbf{P}$, Kharitonov SA, Ciabattoni $G$, et al. Exhaled leukotrienes and prostaglandins in COPD. Thorax 2003:58:585-8.

24 Effros RM, Biller J, Foss B, et al. A simple method for estimating respiratory solute dilution in exhaled breath condensate. Am J Respir Crit Care Med 2003;168:1500-5.

25 Antczak A, Montuschi P, Kharitonov S, et al. Increased exhaled cysteinylleukotrienes and 8-isoprostane in aspirin-induced asthma. Am J Respir Crit Care Med 2002; 166:301-6. 